\title{
Mapeamento da Produção Científica Brasileira sobre Empresas Juniores
}

\author{
Mapping of Brazilian Scientific Production on Junior Companies
}

\author{
Marina Bezerra da Silva ${ }^{1,2}$ \\ Ana Claudia Galvão Xavier ${ }^{1,2}$ \\ Cleide Ane Barbosa da Cruz ${ }^{2}$ \\ Ivanilda de Sousa Rodrigues ${ }^{1}$ \\ Maria Emília Camargo ${ }^{2,3}$ \\ Jonas Pedro Fabris ${ }^{2}$ \\ Ana Eleonora Almeida Paixão ${ }^{2}$ \\ ${ }^{1}$ Instituto Federal do Piauí, Teresina, PI, Brasil \\ ${ }^{2}$ Universidade Federal de Sergipe, São Cristóvão, SE, Brasil \\ ${ }^{3}$ Universidade Caxias do Sul, Caxias do Sul, RS, Brasil
}

\begin{abstract}
Resumo
Este artigo objetivou mapear as produções científicas relacionadas às empresas juniores no Brasil. Foram utilizados os métodos da bibliometria e da análise de conteúdo. A busca de artigos ocorreu por meio das bases brasileiras Scientific Periodicals Electronic Library (Speel) e Scientific Electronic Library Online (SciELO), visando à identificação da literatura nacional acerca do assunto. Foram identificados 28 artigos na base Spell e seis na SciELO, totalizando 34 produções científicas publicadas, no período de 2002 a 2018. Mediante o protocolo utilizado, o estudo identificou que há poucas produções a respeito do assunto no Brasil. Além disso, dentre os principais termos encontrados nos artigos, destacam-se "empresa", "júnior", "aprendizagem", "juniores", "empresas", "empreendedorismo" e "organizacional", refletindo aspectos da aprendizagem técnica geral relacionada aos cursos da área de gestão e negócios e, também, ao desenvolvimento de competências voltadas para o empreendedorismo e para a prática profissional nestas áreas.
\end{abstract}

Palavras-chave: Empresas juniores. Bibliometria. Produção científica.

\begin{abstract}
This article aimed to map the scientific productions related to junior companies in Brazil. Bibliometrics and content analysis methods were used. The search for articles took place through the Brazilian Scientific Periodicals Electronic Library (Speel) and Scientific Electronic Library Online (SciELO) databases, aiming to identify the national literature on the subject. We identified 28 articles in the Spell database and six articles in SciELO, totaling 34 published scientific productions, from 2002 to 2018. Through the protocol used, the study identified that there are few productions about the subject in Brazil. In addition, the main terms found in the articles include "company", "junior", "learning", "juniors", "companies", "entrepreneurship" and "organizational", reflecting aspects of general technical learning related to courses in the area of management and business, and also the development of skills focused on entrepreneurship and professional practice in these areas.
\end{abstract}

Keywords: Junior companies. Bibliometry. Scientific production.

Área Tecnológica: Educação. Formação. Gestão. 


\section{Introdução}

As Empresas Juniores (EJs) são um importante meio de aprendizagem prática para discentes do ensino superior. O empresário júnior será impulsionado pela vivência empresarial, contando com o apoio do quadro docente de Instituições de Ensino Superior, como também de membros e ex-membros de EJs. A Lei n. 13.267, de 6 de abril de 2016, Lei de Empresas Juniores, art. $2^{\circ}$, define estas organizações como associações civis geridas por estudantes matriculados em cursos de graduação de instituições de ensino superior e que têm como propósito realizar projetos e serviços que contribuam para o desenvolvimento acadêmico e profissional dos associados, capacitando-os para o mercado de trabalho (BRASIL, 2016).

Atualmente, no Brasil, estas empresas tiveram um crescimento expressivo, sendo mais de 600 EJs, segundo dados da Brasil Júnior - Confederação Brasileira de Empresas Juniores (2019). Esse crescimento é importante para a preparação dos discentes para o mercado de trabalho, pois alunos que atuam em EJs têm a possibilidade de desenvolver a capacidade de aliar a teoria à prática, o que está além das aulas da graduação. Dada a relevância das empresas juniores, funda-se o problema desta pesquisa, a saber: como está o panorama de produções científicas acerca do tema no país?

Neste sentido, este trabalho objetivou mapear as produções científicas relacionadas às empresas juniores no Brasil. Buscou-se traçar um panorama teórico dos estudos sobre a temática, contribuindo para a compreensão do papel das empresas juniores e de suas peculiaridades.

Este estudo se justifica pela necessidade de obter e divulgar no meio acadêmico mais conhecimento sobre as EJs, visto que o tema ainda é pouco explorado. Além disso, estas informações podem colaborar na preparação do empresário júnior para o mercado de trabalho.

\section{Referencial Teórico}

As empresas juniores correspondem a associações civis sem fins lucrativos, vinculadas às instituições de ensino, que são gerenciadas por estudantes de graduação e contam com o auxílio de professores e, algumas vezes, de profissionais externos à instituição (VALE; CÂNDIDO; ANDRADE, 2017).

Ziliotto e Berti (2012) destacam que este tipo de empresa possui diretoria executiva, conselho de administração, estatuto e um regimento próprio, tendo uma gestão autônoma em relação à Instituição em que residem.

Segundo Silva (2012), o Movimento Empresa Júnior (MEJ) iniciou-se na França em 1967, por meio dos discentes da École Supérieure des Sciences Économiques et Commerciales - ESSEC, em Paris, que criaram a Junior Enterprise visando que os alunos aplicassem o conhecimento adquirido ao longo do curso. Esse movimento possibilitou a expansão das empresas juniores em outros países e o desenvolvimento de uma associação que buscou o fortalecimento dessas empresas nas instituições de ensino superior ao redor do mundo.

Já na década de 1980, o modelo francês foi levado para Suíça, Bélgica, Espanha, Estados Unidos da América e trazido, também, para o Brasil. Em 1990, foi fundada a Junior Association for Development in Europe (JADE), que envolve a confederação europeia de empresas juniores, 
que busca lutar para alcançar os objetivos do movimento junto à União Europeia, visando a troca de experiências com as empresas dos demais continentes (SILVA, 2012).

Com relação ao Brasil, o movimento iniciou em 1987, por meio do Diretor da Câmara de Comércio França-Brasil, João Carlos Chaves, que anunciou na mídia um convite para que interessados pudessem realizar a implantação em suas universidades da Empresa Júnior. Os primeiros interessados foram os estudantes de Administração de Empresas da Fundação Getúlio Vargas de São Paulo (TOSTA et al., 2011).

Segundo a Confederação Brasil Júnior (2019), o País conta com 25 federações, mais de 600 empresas juniores e mais de 20 mil empresários juniores. Ainda, no Brasil, as empresas juniores são disciplinadas pela Lei n. 13.267, de 6 de abril de 2016, que condiciona o seu desenvolvimento e organização.

A Lei n. 13.267 destaca que as empresas juniores devem ser geridas por estudantes matriculados em cursos de graduação, visando que estes possam realizar projetos e serviços que contribuam para seu desenvolvimento acadêmico e profissional, possibilitando a capacitação discente para o mercado de trabalho (BRASIL, 2016).

Dessa forma, entende-se que estas empresas têm um papel importante na formação de alunos de graduação, visto que permitem que eles trabalhem a prática a partir dos conhecimentos adquiridos em sala de aula.

\section{Metodologia}

Com o intuito de identificar as produções acadêmicas referentes à temática sobre empresas juniores, foi realizado o mapeamento de artigos científicos acerca do assunto. Para isto, esta pesquisa ocorreu em duas etapas: inicialmente, uma bibliometria (LOPES et al., 2012), com a contagem de determinados parâmetros da produção científica identificada. Posteriormente, uma análise de conteúdo dos trabalhos mais citados identificados na bibliometria, o que se constitui em "uma metodologia de pesquisa usada para descrever e interpretar o conteúdo de toda classe de documentos e textos" (MORAES, 1999). Proposta similar foi encontrada em Bervanger e Visentini (2016), com um estudo bibliométrico e uma análise de conteúdo de trabalhos sobre empresas juniores publicados em anais de eventos e em periódicos brasileiros.

A busca de artigos científicos foi feita nas bases brasileiras Scientific Periodicals Electronic Library $(\text { Speel })^{1}$ e Scientific Electronic Library Online $(\text { SciELO })^{2}$, visando à identificação da literatura nacional acerca do assunto.

A investigação ocorreu em agosto de 2019, inserindo-se os termos "empresa júnior", "empresas juniores" e "empresários juniores" no campo de busca "título" de ambas as bases. Além disso, como conector foi utilizado o operador lógico booleano "OR", que representa a ideia de agrupamento. Ressalta-se que, inicialmente, os termos também foram inseridos no campo de busca "resumo" das bases, porém não se obteve resultados satisfatórios, recuperando-se trabalhos não atinentes à temática estudada. As expressões de busca utilizadas encontram-se no Quadro 1.

1 A Spell é uma biblioteca eletrônica desenvolvida pela Associação Nacional de Pós-Graduação e Pesquisa em Administração (ANPAD), em parceria com o Instituto Brasileiro de Estudos e Pesquisas Sociais (IBEPES).

2 A SciELO foi desenvolvida a partir de projeto da Fundação de Amparo à Pesquisa do Estado de São Paulo (FAPESP) em parceria com o Centro Latino-Americano e do Caribe de Informação em Ciências da Saúde (BIREME). 
Quadro 1 - Expressão de busca utilizada no estudo

\begin{tabular}{|c|c|c|}
\hline BASE & EXPRESSÃo DE BUSCA \\
\hline Spell & TÍTULO empresas juniores OU TÍTULO empresa júnior OU TÍTULO empresários juniores \\
\hline SciELO & (ti:("empresas juniores" OR "empresa júnior" OR "empresários juniores")) \\
\hline
\end{tabular}

Nota: Quanto à sintaxe da SciELO: o índice "ti" corresponde ao "título do artigo"; a informação dos termos entre aspas " " captura resultados exatamente iguais aos buscados (em relação às palavras e sequências); os parênteses ( ) agrupam as combinações de palavras-chave utilizadas.

Fonte: Dados da pesquisa (2019)

Para a operacionalização da contagem bibliométrica, foram utilizadas a Lei de Zipf, que faz a contagem de palavras do texto, a Lei de Lotka, que mensura a produtividade dos autores, e a Lei de Bradford, que contabiliza a difusão do conhecimento através de publicações em periódicos (ARAÚJO, 2006).

Foram quantificadas informações referentes aos anos das publicações, autores mais produtivos, estados originários das pesquisas, periódicos que mais publicaram sobre o assunto $e$ palavras-chave utilizadas. Para a coleta de informações sobre os autores, acessou-se a Plataforma Lattes. Para a coleta de informações sobre os Qualis dos periódicos, acessou-se a Plataforma Sucupira.

$\mathrm{Na}$ análise de conteúdo, por sua vez, foram observados os objetivos e resultados dos trabalhos mais citados (artigos que já registraram três ou mais citações). Para esta etapa, categorizou-se os objetivos e principais resultados das pesquisas.

Os resultados e discussões do estudo são apresentados em forma de gráficos e tabelas, a seguir.

\section{Resultados e Discussão}

Nos próximos itens, serão explanados os resultados da análise bibliométrica e da análise de conteúdo.

\subsection{Análise Bibliométrica}

Inicialmente, seguindo-se os aspectos metodológicos, procedeu-se com a busca nas bases Spell e SciELO. A Spell apresentou 28 documentos sobre empresas juniores, enquanto a SciELO recuperou seis artigos, indicados na Tabela 1.

Tabela 1 - Número de trabalhos sobre empresas juniores por base de artigos científicos

\begin{tabular}{cc} 
Base & $\mathbf{N}^{\circ}$ DE TrabalHos \\
Spell & 28 \\
SciELO & 06 \\
\hline
\end{tabular}

Fonte: Dados da pesquisa (2019)

As empresas juniores representam experiências práticas para alunos de graduação, que podem começar uma carreira profissional encontrando ali os desafios e as oportunidades da área de formação, bem como desenvolvendo competências, habilidades e atitudes. Bervanger 
e Visentini (2016), entretanto, em análise bibliométrica sobre este assunto, constataram que há poucos estudos sobre a temática das empresas juniores no Brasil. Neste sentido, o assunto representa um oportuno campo de pesquisa.

Com base no quantitativo de artigos identificados, utilizou-se a base Spell para o desenvolvimento deste estudo bibliométrico. A Figura 1, a seguir, apresenta o quantitativo de trabalhos publicados por ano.

Figura 1 - Trabalhos sobre empresas juniores por ano

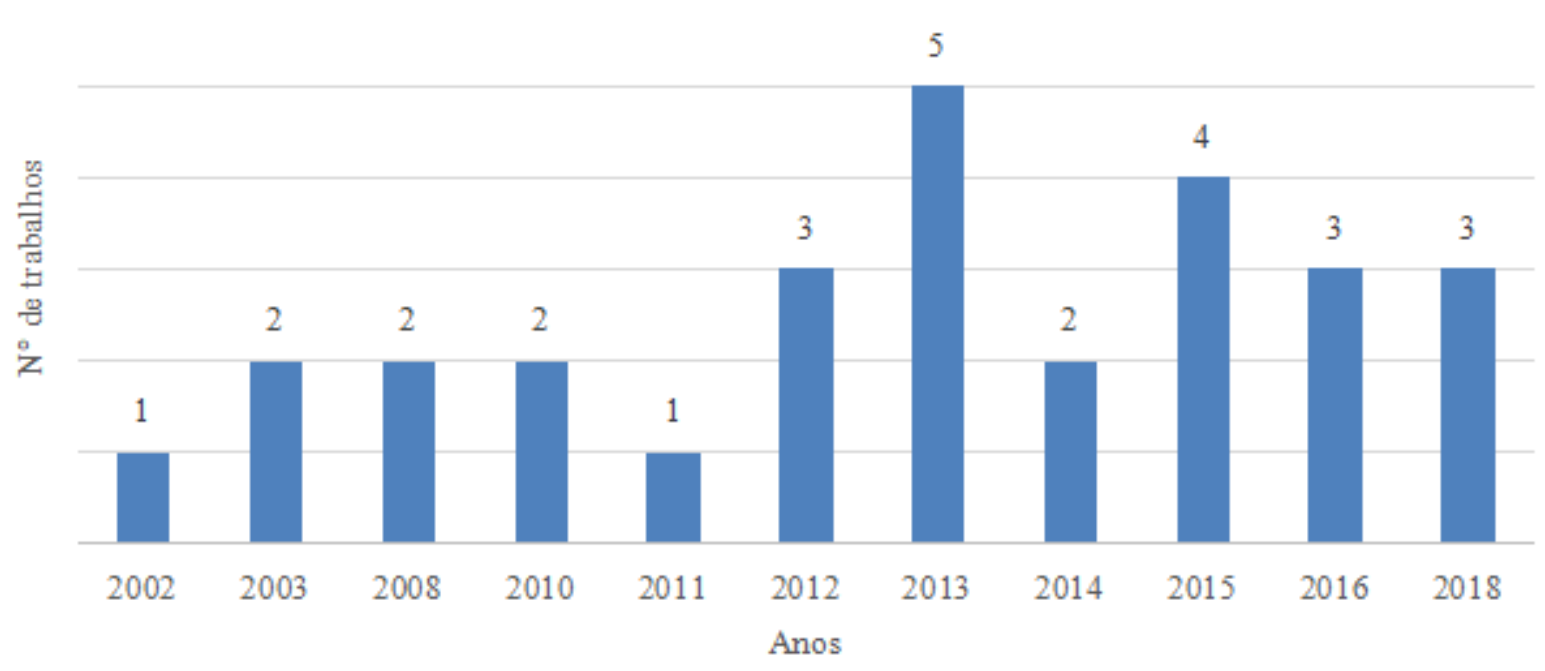

Fonte: Dados da pesquisa (2019)

Com relação aos anos das pesquisas, verifica-se que em 2002 houve a primeira publicação sobre o assunto. Foi a pesquisa de Bernardo e Madeira (2002), que teve como objetivo a elaboração de um balanço social para empresas juniores, bem como a criação de um banco de dados destinado às instituições que precisassem de ajuda e para aqueles que pudessem ajudar. Este estudo apresenta uma importante visão sobre as empresas juniores, enquanto instituições sem fins lucrativos, mas que focam seus esforços na prestação de serviços pelos estudantes, com acompanhamento de seus professores, num processo de aprendizado e crescimento profissional dos discentes envolvidos.

A partir de 2012 houve um aumento no volume de publicações referentes às empresas juniores. Este aspecto pode estar relacionado a um debate instaurado sobre os benefícios gerados pelas empresas juniores na formação acadêmica dos alunos de cursos superiores, conforme mencionado por Vale, Cândido e Andrade (2017). Além disso, outro importante fator foi o debate gerado para elaboração, proposição e aprovação da Lei n. 13.267, de 6 de abril de 2016, que passou a disciplinar a "criação e a organização das associações denominadas empresas juniores", no âmbito das instituições de ensino superior (BRASIL, 2016). A Figura 2, a seguir, apresenta os autores mais produtivos sobre o assunto. 
Figura 2 - Trabalhos sobre empresas juniores por autores

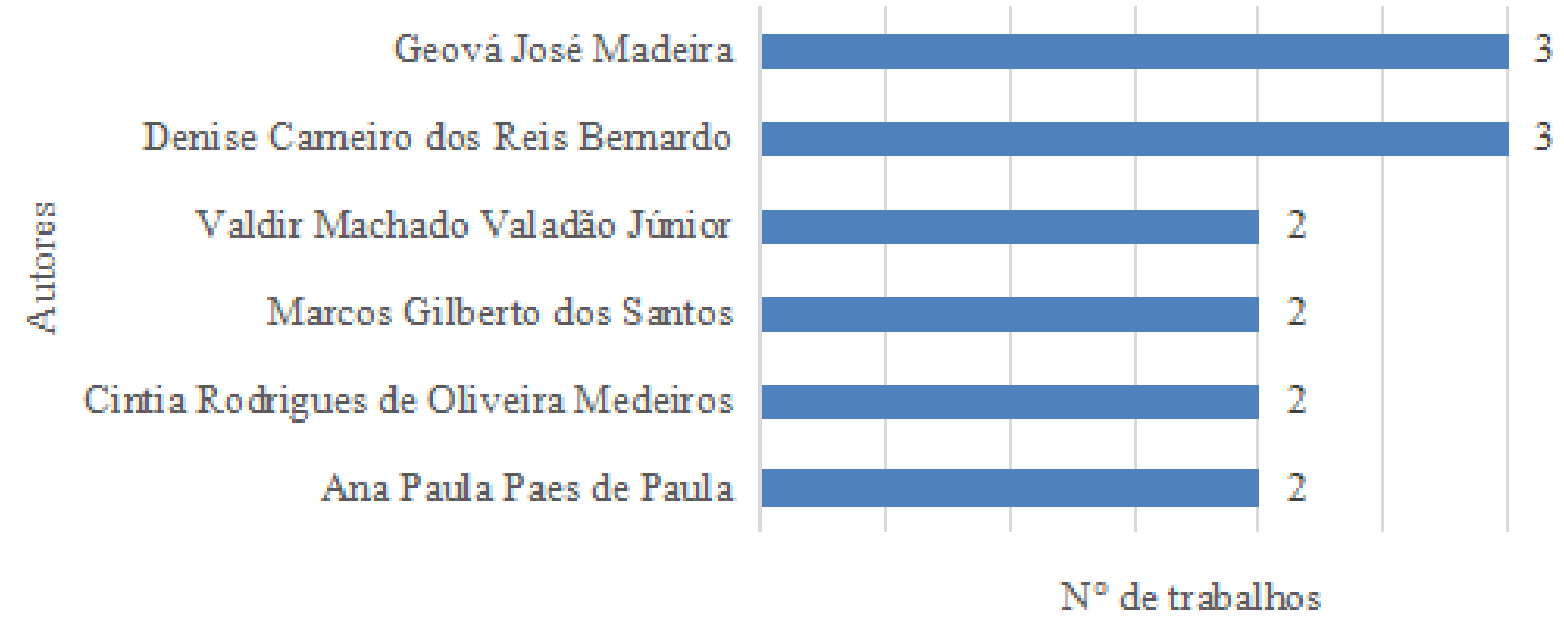

Fonte: Dados da pesquisa (2019)

A Figura 2 apresenta o mapeamento dos principais autores, destacando-se Geová José Madeira e Denise Carneiro dos Reis Bernardo como os pesquisadores mais produtivos nesta temática, possuindo 03 (três) trabalhos cada.

Conforme informações extraídas do Lattes, ambos os professores são ou já tiveram vínculos com universidades do Estado de Minas Gerais. Realizaram pesquisas sobre o assunto em parceria e, juntos, fizeram publicações pioneiras sobre o tema das empresas juniores no Brasil. A seguir, a Figura 3 apresenta os cinco Estados mais produtivos no assunto.

Figura 3 - Trabalhos sobre empresas juniores por estados brasileiros

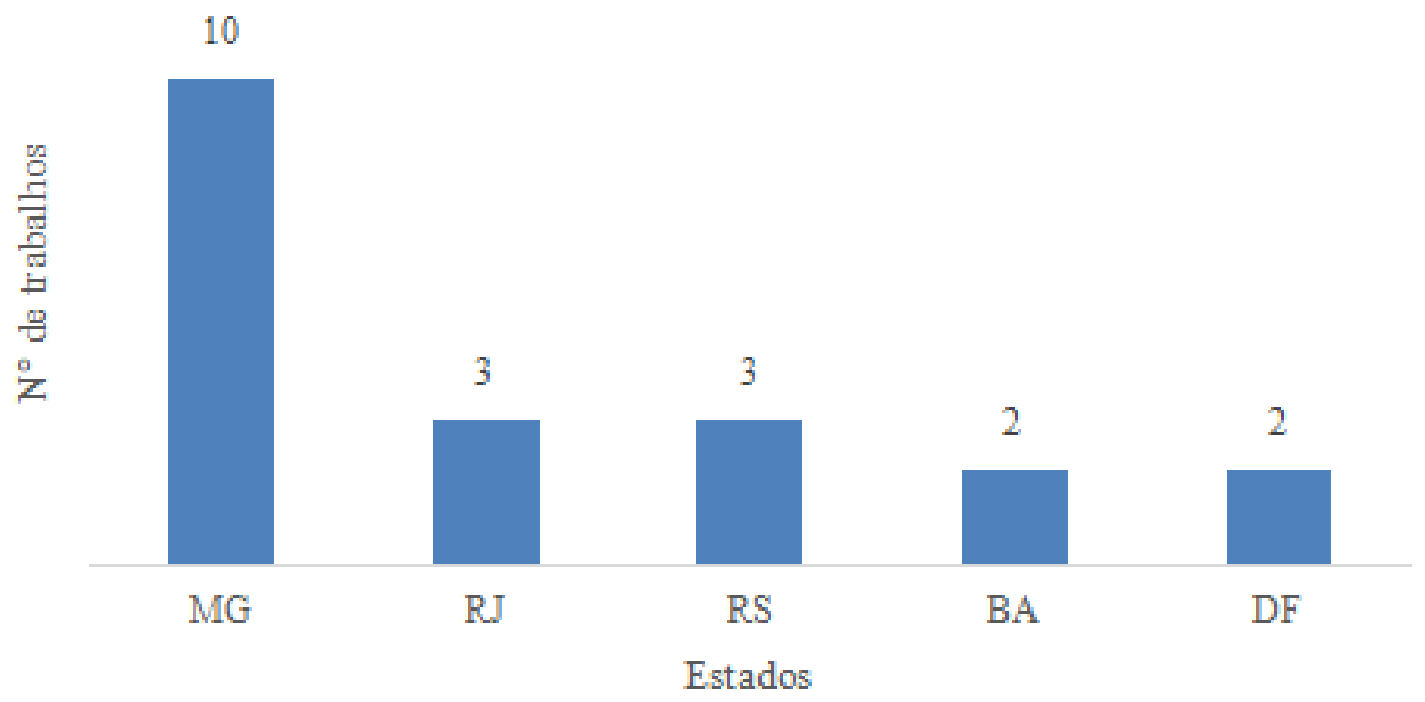

Fonte: Dados da pesquisa (2019) 
Com relação aos Estados, verifica-se que os 05 (cinco) mais produtivos são Minas Gerais, com 10 trabalhos, Rio de Janeiro e Rio Grande do Sul, com 03, Bahia e o Distrito Federal, com 02.

Observa-se que as iniciativas de pesquisa sobre empresas juniores aconteceram nas várias regiões do país, o que está relacionado à difusão que tais projetos tiveram nas instituições acadêmicas brasileiras. Retomando as informações da Brasil Júnior (2019), atualmente existem mais de 600 empresas juniores e mais de 20 mil empresários juniores no país. Neste sentido, o assunto passa a ser oportunidade de pesquisa em várias regiões brasileiras. A Figura 4 apresenta os periódicos que mais publicaram sobre o assunto.

Figura 4 - Trabalhos sobre empresas juniores por periódicos

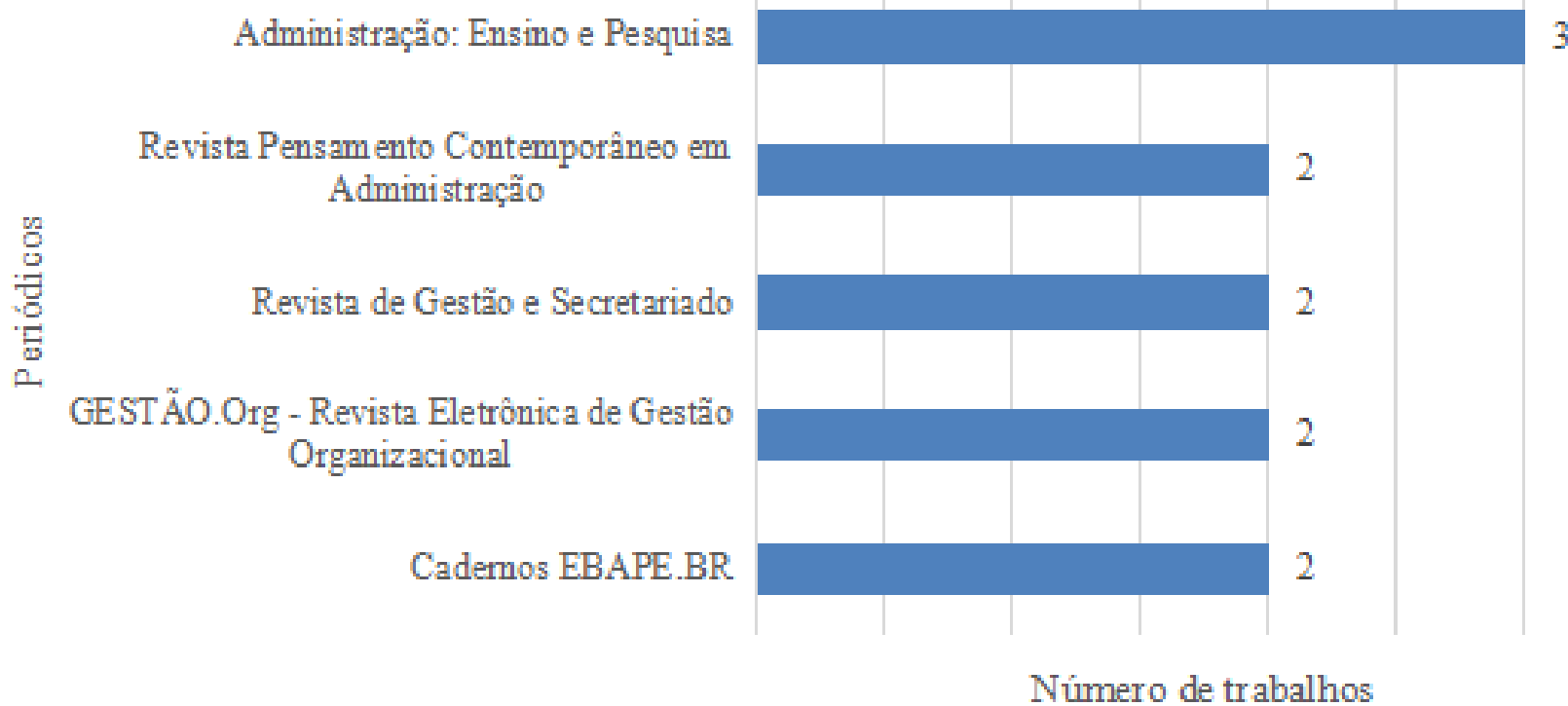

Fonte: Dados da pesquisa (2019)

Mediante a busca realizada, o periódico científico que possui a maior quantidade de trabalhos sobre o assunto é a Revista Administração: Ensino e Pesquisa (RAEP), com 03 documentos. A RAEP está vinculada à Associação Nacional dos Cursos de Graduação em Administração (ANGRAD).

No quadriênio de avaliação de periódicos de 2013 a 2016, da Coordenação de Aperfeiçoamento de Pessoal de Nível Superior (CAPES), a RAEP obteve Qualis B1 na área de Administração Pública e de Empresas, Ciências Contábeis e Turismo e B2 na área Interdisciplinar.

Com relação às palavras-chave dos artigos identificados, apresenta-se a nuvem seguinte (Figura 5). 
Figura 5 - Nuvem das palavras-chave dos artigos

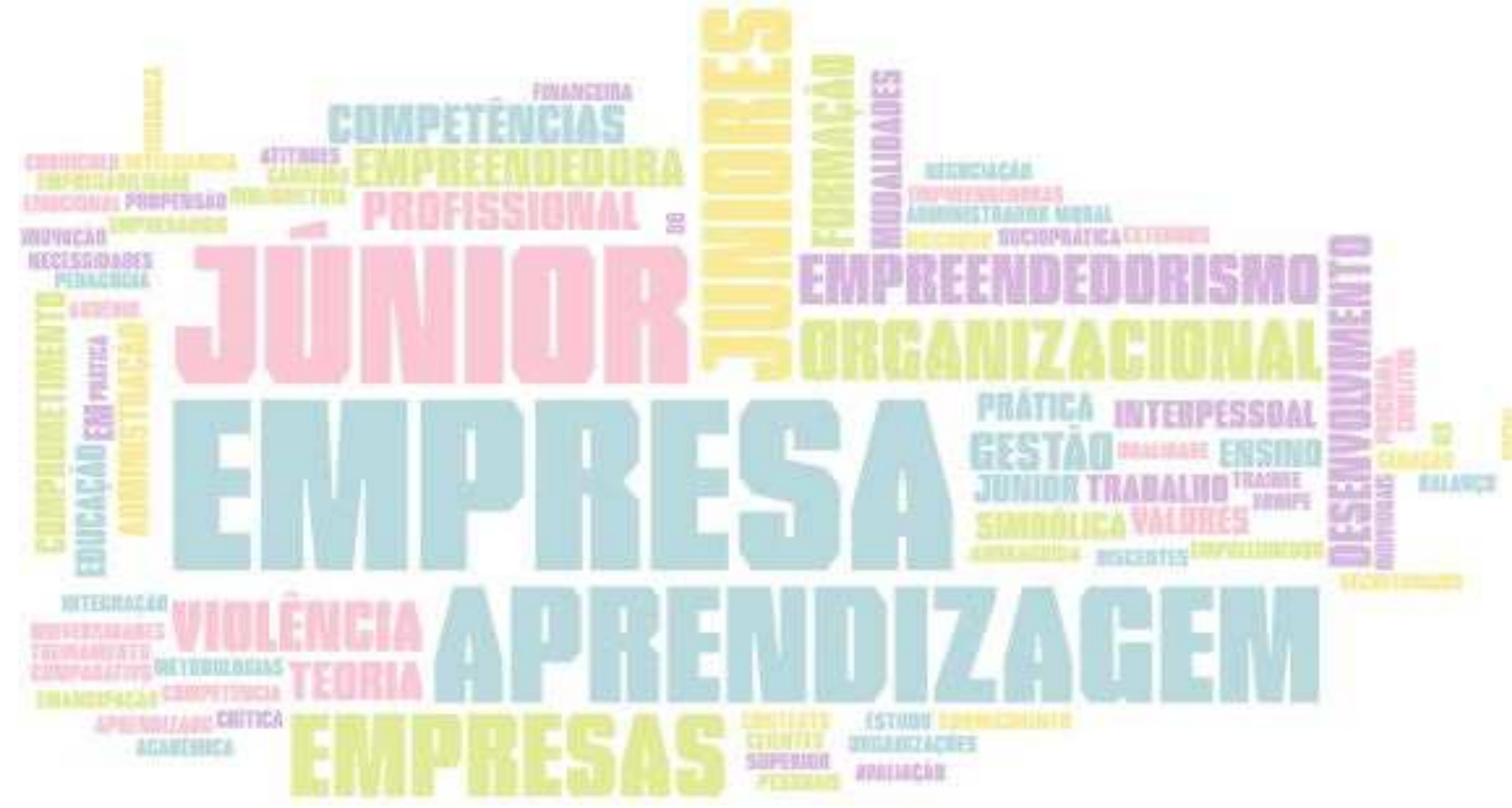

Fonte: Dados da pesquisa (2019)

Através da nuvem, verifica-se o destaque das palavras "empresa”, "júnior”, "aprendizagem”, "juniores", "empresas", "empreendedorismo" e "organizacional".

De modo geral, são termos relacionados aos propósitos das empresas juniores, de proporcionar aos discentes a "associação entre os conhecimentos teóricos aprendidos em sala de aula e a realidade prática do trabalho que eles se propõem a desenvolver" (BICALHO; PAULA, 2012). Enquadram-se, assim, aspectos da aprendizagem técnica geral relacionada aos cursos da área de gestão e negócios e, também, ao desenvolvimento de competências voltadas para o empreendedorismo e para a prática profissional nestas áreas. Vale, Cândido e Andrade (2017), a este respeito, assinalam que nas empresas juniores os alunos praticam aquilo que aprendem em sala. Além disso, podem administrar empresas, desenvolver projetos em equipe, realizar atividades de negociação e de tomada de decisão, sendo responsáveis pela empresa.

O trabalho mais citado foi "Relação entre Valores Pessoais e Comprometimento Organizacional: O Caso das Empresas Juniores de Santa Maria", de Rodrigues et al. (2010). Esta pesquisa recebeu cinco citações e fez uma abordagem sobre os valores pessoais e comprometimento organizacional por parte de membros de empresas juniores. Além disso, está publicada no periódico "GESTÃO.Org - Revista Eletrônica de Gestão Organizacional”.

\subsection{Análise de Conteúdo}

Complementar ao estudo bibliométrico, optou-se por inserir a análise de conteúdo dos sete artigos mais citados na base Spell, para tal utilizaram-se os textos de: Santos et al. (2013), Ferreira-da-Silva e Paula (2011), Bicalho e Paula (2012), Rodrigues et al. (2010), Guimarães, Moreira e Baeta (2013), Lemos, Costa e Viana (2012) e Medeiros, Medeiros e Valadão Júnior (2014), indicados no Quadro 2. 
Quadro 2 - Objetivos e resultados dos artigos mais citados

\begin{tabular}{|c|c|c|c|c|}
\hline $\begin{array}{l}\text { Número } \\
\text { dE } \\
\text { CitAÇõES }\end{array}$ & Título Do ARTIGo & $\begin{array}{l}\text { Autores/ } \\
\text { Periódico }\end{array}$ & Oвjetivos & Resultados \\
\hline 5 & $\begin{array}{c}\text { Relação entre } \\
\text { Valores Pessoais e } \\
\text { Comprometimento } \\
\text { Organizacional: } \\
\text { O Caso das } \\
\text { Empresas Juniores } \\
\text { de Santa Maria }\end{array}$ & $\begin{array}{l}\text { Rodrigues et } \\
\text { al. (2010) } \\
\text { Periódico: } \\
\text { GESTÃO. } \\
\text { Org - Revista } \\
\text { Eletrônica } \\
\text { de Gestão } \\
\text { Organizacional }\end{array}$ & $\begin{array}{c}\text { Verificar se } \\
\text { existe relação } \\
\text { entre os valores } \\
\text { pessoais e o } \\
\text { comprometimento } \\
\text { organizacional } \\
\text { em membros de } \\
\text { empresas juniores. }\end{array}$ & $\begin{array}{c}\text { A pesquisa mostrou que as correlações } \\
\text { apresentadas entre os valores } \\
\text { pessoais e o comprometimento } \\
\text { organizacional não foram consideradas } \\
\text { significativas. Utilizou-se como } \\
\text { parâmetros de relação os valores } \\
\text { pessoais (obediência, prestígio e } \\
\text { convivência) e o comprometimento } \\
\text { organizacional (afetivo, afiliativo, } \\
\text { normativo). Nenhum dos modelos } \\
\text { obtidos nas análises estatísticas } \\
\text { apresentou alto grau de explicação, } \\
\text { indicando que não existe efeito } \\
\text { significativo dos valores pessoais sobre } \\
\text { o comprometimento organizacional. }\end{array}$ \\
\hline 5 & $\begin{array}{l}\text { Como aprendem } \\
\text { os empresários } \\
\text { juniores no } \\
\text { Brasil: um estudo } \\
\text { quantitativo sobre } \\
\text { as modalidades } \\
\text { de aprendizagem } \\
\text { organizacional }\end{array}$ & $\begin{array}{c}\text { Santos et } \\
\text { al. (2013) } \\
\text { Periódico: } \\
\text { Revista Gestão } \\
\text { \& Planejamento }\end{array}$ & $\begin{array}{c}\text { Analisar como } \\
\text { ocorre a } \\
\text { aprendizagem } \\
\text { dos empresários } \\
\text { juniores no Brasil. }\end{array}$ & $\begin{array}{l}\text { A pesquisa mostrou que os empresários } \\
\text { juniores aprendem a partir de } \\
\text { duas abordagens de aprendizagem } \\
\text { organizacional: a individual-cognitivista } \\
\text { (leitura de textos, acesso à banco } \\
\text { de dados e treinamento expositivo } \\
\text { tradicional) e a socioprática (interação } \\
\text { casual, comunidades de prática, } \\
\text { treinamento on-the-job e mentoria). } \\
\text { Identificou-se que a modalidade mais } \\
\text { utilizada é a Mentoria. Outros resultados } \\
\text { da pesquisa são que: as abordagens } \\
\text { sociopráticas explicam a maior parcela } \\
\text { da aprendizagem. As empresas } \\
\text { juniores mostram-se ser um campo } \\
\text { promissor para a formação acadêmico- } \\
\text { profissional dos seus participantes. }\end{array}$ \\
\hline 3 & $\begin{array}{l}\text { Empresa Júnior } \\
\text { e a reprodução } \\
\text { da ideologia da } \\
\text { Administração }\end{array}$ & $\begin{array}{c}\text { Bicalho e } \\
\text { Paula (2012) } \\
\text { Periódico: } \\
\text { Cadernos } \\
\text { EBAPE.BR }\end{array}$ & $\begin{array}{l}\text { Analisar o papel } \\
\text { das empresas } \\
\text { juniores na } \\
\text { formação dos } \\
\text { administradores. }\end{array}$ & $\begin{array}{l}\text { A pesquisa evidenciou que o discurso } \\
\text { do aprendizado é utilizado como } \\
\text { subterfúgio para o estabelecimento de } \\
\text { violências interpessoais e simbólicas } \\
\text { no ambiente da empresa júnior. Na } \\
\text { pretensão de se enquadrar ao padrão } \\
\text { socialmente difundido, materializado } \\
\text { nas cobranças empreendidas entre } \\
\text { os empresários juniores, os sujeitos } \\
\text { aderem à ideologia da administração. }\end{array}$ \\
\hline 3 & $\begin{array}{c}\text { A negociação } \\
\text { com clientes nas } \\
\text { Empresas Juniores } \\
\text { da Universidade } \\
\text { Federal de } \\
\text { Viçosa - Campus } \\
\text { Viçosa (MG) }\end{array}$ & $\begin{array}{c}\text { Guimarães, } \\
\text { Moreira e } \\
\text { Baeta (2013) } \\
\text { Periódico: } \\
\text { Revista de } \\
\text { Administração } \\
\text { da Unimep }\end{array}$ & $\begin{array}{l}\text { Analisar a prática } \\
\text { da negociação } \\
\text { com clientes } \\
\text { externos e } \\
\text { a gestão do } \\
\text { conhecimento nas } \\
\text { Empresas Juniores } \\
\text { da Universidade } \\
\text { Federal de } \\
\text { Viçosa (UFV). }\end{array}$ & $\begin{array}{l}\text { Constatou-se que a maioria das } \\
\text { empresas não possui treinamentos } \\
\text { específicos em negociação. O } \\
\text { conhecimento é repassado aos } \\
\text { novos integrantes por meio do } \\
\text { acompanhamento dos empresários } \\
\text { mais experientes. No caso da gestão } \\
\text { do conhecimento, os métodos } \\
\text { mais utilizados são os relatórios } \\
\text { dos projetos ou consultorias e as } \\
\text { capacitações em áreas afins. }\end{array}$ \\
\hline
\end{tabular}




\begin{tabular}{|c|c|c|c|c|}
\hline $\begin{array}{l}\text { Número } \\
\text { DE } \\
\text { CITAÇốES }\end{array}$ & Título do ARTigo & $\begin{array}{l}\text { Autores/ } \\
\text { Periódico }\end{array}$ & Objetivos & Resultados \\
\hline 3 & $\begin{array}{c}\text { Empregabilidade } \\
\text { e inserção } \\
\text { profissional: } \\
\text { expectativas } \\
\text { e valores dos } \\
\text { participantes de } \\
\text { empresas juniores }\end{array}$ & $\begin{array}{c}\text { Lemos, Costa e } \\
\text { Viana (2012) } \\
\\
\text { Periódico: } \\
\text { Revista } \\
\text { Pensamento } \\
\text { Contemporâneo } \\
\text { em } \\
\text { Administração }\end{array}$ & $\begin{array}{l}\text { Identificar os } \\
\text { principais valores } \\
\text { que motivam } \\
\text { e orientam } \\
\text { as escolhas } \\
\text { profissionais dos } \\
\text { jovens que optam } \\
\text { por integrar as } \\
\text { empresas juniores. }\end{array}$ & $\begin{array}{l}\text { A pesquisa apontou que um grupo } \\
\text { expressivo de integrantes das empresas } \\
\text { juniores revelam que valorizam: o } \\
\text { pensamento e ação independentes; } \\
\text { necessidade de variedade; sucesso } \\
\text { e autorrealização pessoal através } \\
\text { da demonstração de competência } \\
\text { profissional; obtenção de uma posição } \\
\text { dominante; e autogratificação, e isto os } \\
\text { orienta à opção por trabalhar nessas } \\
\text { empresas. Entretanto, preocupações } \\
\text { com a qualidade de vida, a conduta } \\
\text { ética e a responsabilidade social } \\
\text { empresarial não tiveram destaque nas } \\
\text { falas dos participantes da pesquisa. }\end{array}$ \\
\hline 3 & $\begin{array}{l}\text { Organização de } \\
\text { aprendizagem } \\
\text { em uma Empresa } \\
\text { Júnior }\end{array}$ & $\begin{array}{c}\text { Ferreira-da-Silva } \\
\text { e Pinto (2011) } \\
\\
\text { Periódico: } \\
\text { Administração: } \\
\text { Ensino e } \\
\text { Pesquisa }\end{array}$ & $\begin{array}{l}\text { Analisar como } \\
\text { uma empresa } \\
\text { júnior caracteriza- } \\
\text { se como uma } \\
\text { organização de } \\
\text { aprendizagem. }\end{array}$ & $\begin{array}{l}\text { A pesquisa partiu da ligação entre as } \\
\text { cinco disciplinas de Senge (1990) e } \\
\text { as noções de aprendizagem vivencial. } \\
\text { Revela-se que a organização domina } \\
\text { as disciplinas de nível individual de } \\
\text { Senge (Domínio Pessoal e Modelos } \\
\text { Mentais), identificando-se certo esforço } \\
\text { para desenvolver o domínio das } \\
\text { disciplinas, que tratam do nível coletivo } \\
\text { (Objetivo Comum, Aprendizado em } \\
\text { Grupo e Pensamento Sistêmico). }\end{array}$ \\
\hline 3 & $\begin{array}{l}\text { Âncoras de } \\
\text { Carreira e Geração } \\
\text { Y: um estudo com } \\
\text { consultores de } \\
\text { empresas juniores }\end{array}$ & $\begin{array}{c}\text { Medeiros, } \\
\text { Medeiros e } \\
\text { Valadão Júnior } \\
\text { (2014) } \\
\text { Periódico: } \\
\text { ReCaPe Revista } \\
\text { de Carreiras } \\
\text { e Pessoas }\end{array}$ & $\begin{array}{c}\text { Identificar a } \\
\text { orientação de } \\
\text { carreira da } \\
\text { Geração Y, de } \\
\text { consultores de } \\
\text { empresas juniores } \\
\text { de Minas Gerais, } \\
\text { à luz do modelo } \\
\text { de Schein (1996). }\end{array}$ & $\begin{array}{l}\text { A pesquisa utilizou o instrumento } \\
\text { elaborado por Schein (1996) para } \\
\text { identificar as âncoras de carreira } \\
\text { (aptidão técnico-funcional, aptidão } \\
\text { administrativa geral, autonomia/ } \\
\text { independência, segurança/estabilidade, } \\
\text { criatividade empreendedora, vontade } \\
\text { de servir/dedicação a uma causa, } \\
\text { puro desafio e estilo de vida). Como } \\
\text { resultado, houve uma tendência } \\
\text { de estabelecer como ponto de } \\
\text { referência a âncora Estilo de Vida. } \\
\text { Contudo, conforme esclarecido } \\
\text { por Schein (1996), ao contrário do } \\
\text { que possa parecer, os indivíduos } \\
\text { são altamente motivados em suas } \\
\text { carreiras, mas desejam que ela se } \\
\text { integre ao estilo de vida adotado. } \\
\text { Evidenciando-se que as preferências } \\
\text { dos participantes corroboram as } \\
\text { características gerais típicas da } \\
\text { personalidade coletiva da Geração Y. }\end{array}$ \\
\hline
\end{tabular}

Fonte: Dados da pesquisa (2019)

Santos et al. (2013), Ferreira-da-Silva e Paula (2011) e Bicalho e Paula (2012) analisaram, em suas pesquisas, como ocorre o processo de aprendizagem dos integrantes das empresas juniores. O primeiro destacou, em seu trabalho, duas abordagens da aprendizagem organizacional: a individual-cognitivista (leitura de textos, acesso à banco de dados e treinamento expositivo 
tradicional) e a socioprática, nas modalidades mentoria, interação casual, comunidades de prática e treinamento on-the-job, identificando a mentoria como a mais utilizada pelos estudantes.

Ferreira-da-Silva e Paula (2011), por sua vez, partiram da ligação entre as cinco disciplinas do aprendizado de Senge (1990) e as noções de aprendizagem vivencial. Verificaram o predomínio de disciplinas em nível individual na organização da aprendizagem, tais como domínio pessoal e modelos mentais.

É significativo que os alunos participem de atividades como as empresas juniores pelo fato de completar a aprendizagem da sala de aula e ajudar na inserção no mundo do trabalho, estimulando a capacidade gerencial e o contato com estruturas empresariais formais (SANGALETTI; CARVALHO, 2004; JUNKES et al., 2004). Bicalho e Paula (2012), entretanto, salientam que o discurso do aprendizado serve de pretexto para o estabelecimento de violências interpessoais e simbólicas no ambiente da empresa júnior, levando os sujeitos a aderirem à ideologia da administração.

Outros temas abordados nos estudos em evidência dizem respeito à negociação, aos valores e à orientação de carreira. Guimarães, Moreira e Baeta (2013) indicam a necessidade de treinar as gestões das empresas juniores para as negociações com os clientes externos. No entanto, Rodrigues et al. (2010), Lemos, Costa e Viana (2012) e Medeiros, Medeiros e Valadão Júnior (2014) chamam a atenção para as questões dos valores pessoais e sua relação com o comprometimento organizacional, os valores que motivam as escolhas profissionais e, por fim, a identificação da orientação de carreira.

\section{Considerações Finais}

A pesquisa evidenciou por meio das análises bibliométrica e de conteúdo que ainda há pouca produção científica sobre o tema empresas juniores no Brasil, mesmo com o crescimento e com a difusão que estas organizações tiveram nas universidades brasileiras nos últimos anos.

Em 2002, identificou-se o primeiro artigo científico sobre o assunto. A partir de 2012, houve um aumento no volume de publicações referentes ao tema, aspecto que pode estar relacionado ao debate instaurado acerca dos benefícios gerados pelas empresas juniores na formação acadêmica dos alunos de cursos superiores, bem como ao estabelecimento da Lei n. 13.267, de 6 de abril de 2016, que trata sobre este tipo de organização.

É importante que novos estudos sejam realizados sobre empresas juniores, pois estas representam mecanismos de aprendizagem prática, ampliando a vivência do cenário empresarial (gestão e negócios) no âmbito dos cursos superiores das Universidades.

Sugere-se que novos trabalhos sobre o tema utilizem as bases Scopus e Science Direct, visando ao mapeamento de estudos originários de outros países.

\section{Referências}

ARAÚJO, C. A. A. Bibliometria: evolução histórica e questões atuais. Em Questão, v. 12, n. 1, p. 11-32, dez, 2006. 
BERNARDO, D. C. R.; MADEIRA, G. J. Balanço Social: o caso das empresas juniores do estado de Minas Gerais: transformando o tempo em qualidade de vida. Contabilidade Vista \& Revista, v. 13, n. 3, p. 35-52, set./dez. 2002.

BERVANGER, E.; VISENTINI, M. S. Publicações científicas brasileiras sobre empresas juniores na área de administração: um estudo bibliométrico. Revista de Gestão, São Paulo, v. 23, p. 197-210, 2016.

BICALHO, R. A.; PAULA, A. P. P. Empresa júnior e a reprodução da ideologia da administração. Cadernos EBAPE.BR, v. 10, n. 4, p. 894-910, out./dez. 2012.

BRASIL. Lei n ${ }^{\circ}$ 13.267, de 6 de abril de 2016. Disciplina a criação e a organização das associações denominadas empresas juniores, com funcionamento perante instituições de ensino superior. Diário Oficial [da] República Federativa do Brasil. Brasília, DF, 7 abr. 2016. Disponível em: http://www. planalto.gov.br/ccivil_03/_ato2015-2018/2016/lei/L13267.htm. Acesso em: 1 ago. 2019.

BRASIL JÚNIOR. Movimento Empresa Júnior. 2019. Disponível: https://brasiljunior.org.br/ conheca-o-mej. Acesso em: 3 ago. 2019.

FERREIRA-DA-SILVA, R. C.; PINTO, S. R. R. Organização de aprendizagem em uma empresa júnior. Administração: Ensino e Pesquisa, v. 12, n. 1, p. 11-39, jan./mar. 2011.

GUIMARÃES, T. A.; MOREIRA, N. C.; BAETA, O. V. A negociação com clientes nas empresas juniores da Universidade Federal de Viçosa - Campus Viçosa (MG). Revista de Administração da Unimep, v. 11, n. 1, p. 81-103, jan./abr. 2013.

JUNKES, P. N.; ROSAURO, D. Z.; BENKO, F. S. Olhar crítico sobre a gestão das empresas juniores. In: NETO, L. M. et al. (org.) Empresa Júnior: espaço de aprendizagem. Florianópolis: [s.n], 2004.

LEMOS, A. H. C.; COSTA, A. M.; VIANA, M. D. A. Empregabilidade e inserção profissional: expectativas e valores dos participantes de empresas juniores. Revista Pensamento

Contemporâneo em Administração, v. 6, n. 1, p. 91-104, jan./mar. 2012.

LOPES, S.; COSTA, M. T.; FERNÁNDEZ-LLIMÓS, F.; AMANTE, M. J.; LOPES, P. F. A bibliometria $e$ a avaliação da produção científica: indicadores e ferramentas. In: CONGRESSO NACIONAL DE BIBLIOTECÁRIOS, ARQUIVISTAS E DOCUMENTALISTAS, 2012, Lisboa. Anais [...]. Lisboa: 2012.

MEDEIROS, C. R. O.; MEDEIROS, L.; VALADÃO JÚNIOR, V. M. Âncoras de carreira e geração y: um estudo com consultores de empresas juniores. Revista de Carreiras e Pessoas, v. 4, n. 3, p. 212-230, set./dez. 2014.

MORAES, R. Análise de conteúdo. Revista Educação, Porto Alegre, v. 22, n. 37, p. 7-32, 1999.

RODRIGUES, C. M. C.; VIEIRA, K. M.; RIBAS, F. T. T.; ARRUDA, G. S.; CATARINA, G. M. F. S. Relação entre valores pessoais e comprometimento organizacional: o caso das empresas juniores de Santa Maria. GESTÃO.Org - Revista Eletrônica de Gestão Organizacional, v. 8, n. 2, p. 245264, mai./ago. 2010.

SANGALETTI, C.; CARVALHO, G. Introdução ao movimento empresa júnior. In: NETO, L. M. et al. (org.). Empresa Júnior: espaço de aprendizagem. Florianópolis: [s.n.], 2004.

SANTOS, M. G.; JESUS, K . C. B.; SOUZA-SILVA, J. C.; SILVA, V. A.; FRANCO, A. P. Como aprendem os empresários juniores no Brasil: um estudo quantitativo sobre as modalidades de aprendizagem organizacional. Revista Gestão \& Planejamento, v. 14, n. 3, p. 372-388, set./dez. 2013. 
SCHEIN, E. H. Identidade profissional: como ajustar suas inclinações a suas opções de trabalho. Tradução de Margarida D. Black. São Paulo: Nobel, 1996.

SENGER, P. M. A quinta disciplina. 7. ed. São Paulo: Best Seller, 1990.

SILVA, P. C. R. Empresa júnior na prática. Brasília: Kiron, 2012.

TOSTA, K. C. B. T.; JOHANN, K. R.; PACASSA, F.; GEREMIA, L. V.; SILVA, S. M. Empresa júnior e o processo de ensino-aprendizagem prática em administração: o caso da criação da Sem Fronteiras Consultoria Júnior da Universidade Federal da Fronteira Sul. In: COLÓQUIO INTERNACIONAL SOBRE GESTÃO UNIVERSITÁRIA NA AMÉRICA DO SUL, 2011, Florianópolis. Anais [...]. Florianópolis: IGLU, 2011.

VALE, M. A.; CÂNDIDO, A. C.; ANDRADE, A. R. Contribuições de empresas juniores para o ensino universitário. Revista Brasileira de Educação em Ciência da Informação, v. 4, n. 2, p. 58-76, 2017.

ZILIOTTO, D. M.; BERTI, A. R. A aprendizagem do aluno inserido em empresa júnior. Revista Conexão UEPG, v. 8, n. 2, p. 210-217, 2012.

\title{
Sobre os Autores
}

\author{
Marina Bezerra da Silva \\ E-mail: marina.silva@ifpi.edu.br \\ Mestrado em Ciência da Propriedade Intelectual. \\ Endereço profissional: Rua Projetada, s/n, Uberaba II, Oeiras, PI. CEP: 64500-000.
}

\section{Ana Claudia Galvão Xavier}

E-mail: anaclaudia@ifpi.edu.br

Especialista em Programação do Ensino em Pedagogia.

Endereço profissional: Praça da Liberdade, n. 1.597, Centro, Teresina, PI. CEP: 64000-040.

\section{Cleide Ane Barbosa da Cruz}

E-mail: cleideane.barbosa@bol.com.br Mestrado em Ciência da Propriedade Intelectual.

Endereço profissional: Rod. Antônio Carlos Valadares, s/n, Tobias Barreto, SE. CEP: 49300-000.

\section{Ivanilda de Sousa Rodrigues}

E-mail: hivanilda.hale@gmail.com

Bacharelanda em Administração.

Endereço profissional: Rua Projetada, s/n, Uberaba II, Oeiras, PI. CEP: 64500-000.

\section{Maria Emília Camargo}

E-mail: mariaemiliappga@gmail.com

Doutorado em Engenharia de Produção.

Endereço Profissional: Av. João Machado Soares, n. 3.199, Santa Maria, RS. CEP: 97110-000. 


\section{Jonas Pedro Fabris}

E-mail: jpfabris@hotmail.com

Doutor em Ciência da Propriedade Intelectual.

Endereço profissional: Av. Marechal Rondon, s/n, Jardim Rosa Elze, São Cristóvão, SE. CEP: 49100-000.

\section{Ana Eleonora Almeida Paixão}

E-mail: aepaixao@gmail.com

Doutora em Engenharia Química.

Endereço profissional: Av. Marechal Rondon, s/n, Jardim Rosa Elze, São Cristóvão, SE. CEP: 49100-000. 